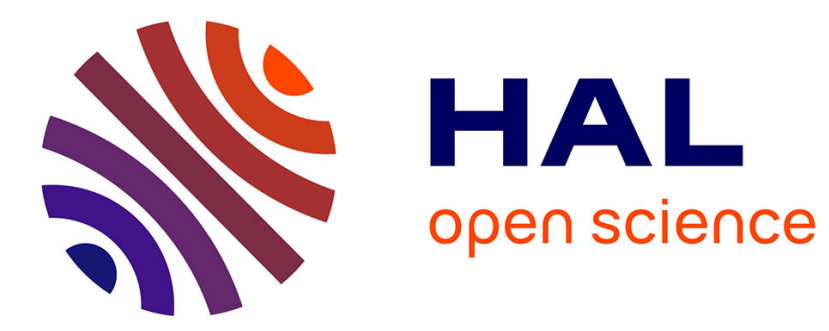

\title{
Improvements in GaAs JFETs for Deep Cryogenic Operation
}

T. Cunningham

\section{To cite this version:}

T. Cunningham. Improvements in GaAs JFETs for Deep Cryogenic Operation. Journal de Physique IV Proceedings, 1996, 06 (C3), pp.C3-231-C3-236. 10.1051/jp4:1996335 jpa-00254253

\section{HAL Id: jpa-00254253 https://hal.science/jpa-00254253}

Submitted on 1 Jan 1996

HAL is a multi-disciplinary open access archive for the deposit and dissemination of scientific research documents, whether they are published or not. The documents may come from teaching and research institutions in France or abroad, or from public or private research centers.
L'archive ouverte pluridisciplinaire HAL, est destinée au dépôt et à la diffusion de documents scientifiques de niveau recherche, publiés ou non, émanant des établissements d'enseignement et de recherche français ou étrangers, des laboratoires publics ou privés. 


\title{
Improvements in GaAs JFETs for Deep Cryogenic Operation
}

\author{
T.J. Cunningham
}

Mail Stop 300-315, Jet Propulsion Laboratory, 4800 Oak Grove Drive, Pasadena, CA 91109, U.S.A.

\begin{abstract}
Gallium arsenide junction field-effect transistors (GaAs JFETs) can be made immune to carrier freeze-out, making such transistors useful for the readout of detector arrays that operate at $4 \mathrm{~K}$. Typical applications require transistors with very low noise and extremely low leakage current. By using a recently developed etchant for GaAs that is highly isotropic, etched GaAs JFETs have fabricated that have a gently tapered edge. This reduces edge fields, which consequently reduces the edge tunneling current, the dominant source of leakage current at $4 \mathrm{~K}$. JFETs with gate leakage currents below $10^{-15}$ amps have been fabricated. The fabrication technique, including the isotropic etchant is discussed. The leakage current and noise of these JFETs are presented and compared with previous devices using a conventional etch.
\end{abstract}

\section{INTRODUCTION}

Future American and European space missions will employ detectors cooled to below $4 \mathrm{~K}$. This includes photovoltaic and photoconductive detectors for the very long wavelength infrared (VLWIR, approximately $50 \mu \mathrm{m}$ to $200 \mu \mathrm{m}$ wavelength), as well as many bolometers. For small arrays of such detectors consisting of less than ten pixels, it previously had been adequate to cool only the detector array to $4 \mathrm{~K}$, and to run a wire from each pixel to a warmer compartment containing the readout electronics. These wires carry heat to the cold head, however, and they are susceptible to noise pickup, which makes this approach impractical for larger arrays or for ultra-low noise levels envisioned for future missions.

Therefor, several different groups have been exploring readout electronics that can operate at $4 \mathrm{~K}$ and below, and that can be placed on the cold head immediately adjacent to the detector array[1-5]. Clearly such electronics must circumvent carrier freeze-out and be functional at $4 \mathrm{~K}$. They must also dissipate low power, and have low noise and input current. For the Space Infrared Telescope Facility (SIRTF), for example, the readout electronics are required to dissipate less than $10 \mu \mathrm{W}$ per channel, have less than 100 electrons per second input current, and have an input-referred voltage noise of less than $1 \mu \mathrm{V} / \mathrm{Hz}^{1 / 2}$ at $1 \mathrm{~Hz}$.

We have been exploring GaAs JFET-based electronics for such applications for the past several years[6]. Because of the very small electron effective mass in GaAs, moderately doped $n$-type GaAs can be made immune to carrier freeze-out. We have concentrated on JFETs rather than MESFETs because the higher 
gate barrier provided by the p-n junction in the JFET reduces the gate leakage current relative to metal Schottky gate in a MESFET. The principal challenge has been to reduce the noise and gate leakage current to acceptable levels.

\section{THE DEVICE STRUCTURE.}

The device structure is shown in Fig. 1. The device consists of a p-type gate over n-type channel, an undoped spacer, and a semi-insulating substrate. The layer structure is grown by MBE, and wet chemical etching is used to etch back the layers. Details have been previously discussed [6].

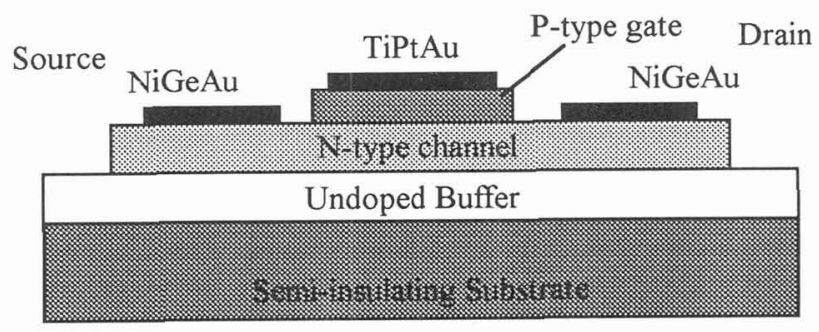

Fig. 1: The structure of the GaAs JFET produced by MBE growth and etch-back. The undoped buffer is approximately $1 \mu \mathrm{m}$ thick. The n-type channel is $3750 \AA$ thick and doped with silicon to $5 \times 10^{16} \mathrm{~cm}^{-3}$. The p-type gate is $500 \AA$ thick and is doped to greater than $5 \times 10^{18} \mathrm{~cm}^{-3}$.

\section{OLD AND NEW GATE ETCH PROCEDURES.}

Previously devices were made using a self-aligned gate etch with an ammonium hydroxide based etch. That is, the Ti-Pt-Au was patterned by lift-off, during which the photoresist was removed. The Ti-Pt-Au metal contact was then used as the mask for the etch that defined the gate. The etchant was a mixture of ammonium hydroxide, hydrogen peroxide and water (11:4:550 by volume). The same etchant was used to make the isolation etch, using a photoresist mask.

This procedure requires only one mask level to create the gate, and it resulted in functional devices. However, there were several problems with it. First, there is some edge roughness in the gate metalization due to the nature of the lift-off process. This edge roughness is duplicated by the etch in the self-aligned process. This surface roughness tends to enhance the field in localized spots. There is also some undercut, and metal filaments can fall over the edge of the gate, forming a small Schottky barrier diodes between the gate metalization and the n-type channel. Both the field enhancement and the parasitic Schottky contacts tend to increase the leakage current.

For this reason, we began fabricating devices using a second procedure. In this procedure, a photoresist mask is used for the gate etch. The gate metalization is still done using lift-off, but in a separate step rather than self-aligned as in the previous procedure. The mask set is designed so that the gate metal edge falls by several microns inside the edge of the p-type GaAs formed by the gate etch.

Additionally, the chemistry of the wet chemical etchant was changed. Mixtures of hydrogen peroxide and an acid or base all work by using the hydrogen peroxide to oxide the GaAs to form gallium oxide and arsenic oxide. These oxides are then dissolved by the acid or base. Even in dilute mixtures, however, these etches are not perfectly isotropic, and can result in a retrograde etch wall profile on the 110 faces.

A new, more isotropic etchant has recently been developed based on an hydrofluoric acid/ hydrogen peroxide/ water system[7]. The peroxide oxidizes the GaAs as before. Ordinarily, arsenic oxides dissolve more rapidly in acid/peroxide solutions. In fact, arsenic oxide has some solubility in pure water. It is 
believed, however, that HF naturally has more of an affinity for gallium oxide. In a dilute solution, this counters the natural tendency for the arsenic oxide to dissolve faster, making the dissolution rates roughly equal. This keeps the etch diffusion limited and consequently isotropic.

The concentration of $2: 10: 1000 \mathrm{HF}: \mathrm{H}_{2} \mathrm{O}_{2}: \mathrm{H}_{2} \mathrm{O}$ was used for the gate etch. The etch rate is approximately $200 \mathrm{~A} / \mathrm{min}$. A slightly less dilute concentration of 2:10:200 was used for the mesa etch. The etch rate of this solution is approximately $2000 \AA / \mathrm{min}$.

\section{A COMPARISON OF JFETS FABRICATED BY THE OLD AND NEW PROCEDURES.}

The gate leakage current vs. gate voltage of JFETs fabricated using the self-aligned procedure with $\mathrm{NH}_{4} \mathrm{OH}$-based etchant was measured using the circuit shown in Fig. 2a. The results for a ring geometry JFET $20 \mu \mathrm{m}$ long and $1250 \mu \mathrm{m}$ in circumference is shown in Fig. 3. The current rises above $1 \mathrm{pA}$ at a gate voltage of approximately $-6.5 \mathrm{~V}$, and increases to almost $1 \mathrm{nA}$ at a gate voltage of $-10 \mathrm{~V}$. The current noise floor of the system is approximately $1 \mathrm{pA}$.

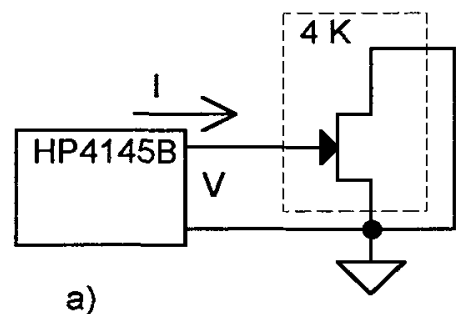

a)

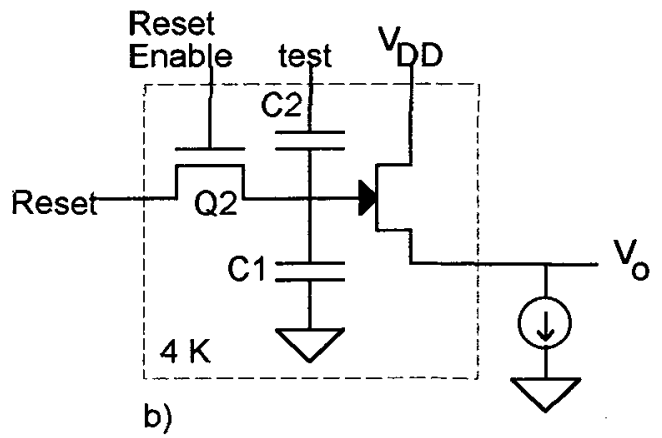

Fig. 2: The circuits used to measure leakage current. Circuit 2a uses a HP4145B semiconductor parameter analyzer as an ammeter to measure gate leakage vs. voltage down to a noise floor of approximately $1 \mathrm{pA}$. Circuit $2 b$ uses the JFET as a source-follower, and integrates the leakage current onto the capacitor set $\mathrm{Cl}$ and $\mathrm{C} 2$. The time rate of change of $\mathrm{V}_{0}$ is proportional to the leakage current.

The current of a rectangular JFET fabricated using the separate gate etch and metalization with the HFbased etchant was also measured using the circuit of Fig. $2 \mathrm{a}$, but the resulting current was less than $1 \mathrm{pA}$ out to a gate voltage of $-15 \mathrm{~V}$. To measure the gate current of this device, it was necessary to use the circuit shown in Fig. 2b. In this circuit, the JFET under test is connected as a source follower. A reset voltage is applied onto the gate of the JFET by turning on Q2, and this voltage is stored on capacitors $\mathrm{Cl}$ and C2. At the start of the integration period, Q2 is turned off, and the gate leakage current of the JFET is integrated on the capacitor set. The change in the gate voltage is reflected in the change of the source follower voltage. The gate leakage current can then be calculated from the rate of change of the source follower voltage using Eq. 1.

$$
I_{\text {leakage }}=\frac{C_{T}}{A_{v}} \frac{d}{d t} V_{o}
$$

where $A_{v}$ is the gain of the source-follower, and $C_{T}$ is the total capacitance of $C 1$ and $C 2$, together with the capacitance of the gate of the JFET and including any parasitic capacitance. For this measurement, $\mathrm{Cl}$ and $\mathrm{C} 2$ were both $1 \mathrm{pF}$. The reset voltage was $1 \mathrm{~V}$, and $\mathrm{V}_{\mathrm{DD}}$ was set to $3 \mathrm{~V}$. The load bias current on the source of the JFET was $10 \mu \mathrm{A}$. 


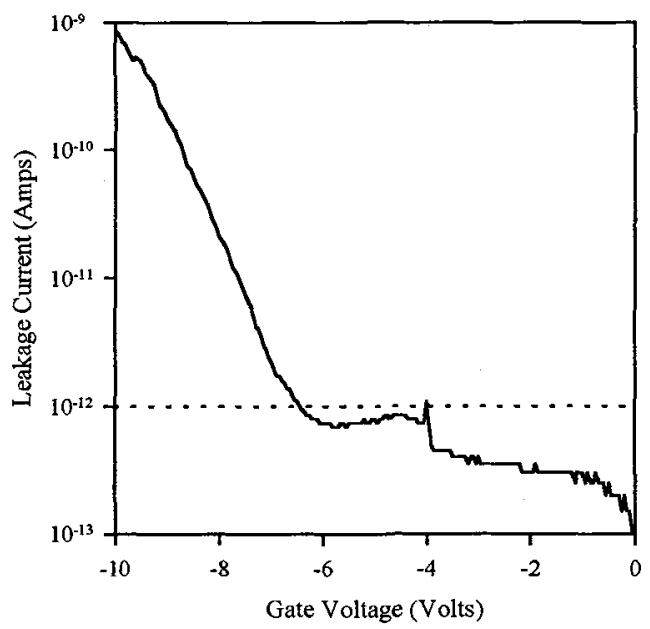

Fig. 3: The gate leakage current as a function of voltage measured using the circuit shown in Fig. 2a, for a ring JFET $1250 \mu \mathrm{m}$ in circumference and $20 \mu \mathrm{m}$ long made using the old, self-aligned process with ammonium hydroxide-based etchant. The noise floor is approximately $1 \mathrm{pA}$.

For an accurate calculation of the leakage current, both $C_{T}$ and $A_{V}$ must be measured. The gain $A_{V}$ was measured by turning on $\mathrm{Q} 2$, sweeping the reset voltage from 0 to $2 \mathrm{~V}$, and recording the output voltage $V_{0}$. With a $10 \mu \mathrm{A}$ load current, the gain of the source follower circuit is $A_{v}=0.9435$.

The capacitance was measured by injecting a $1 \mathrm{kHz} \mathrm{AC}$ signal on the test point connected to $\mathrm{C} 2$. The circuit then forms a capacitive divider between $\mathrm{C} 2$, and the remaining capacitance $\mathrm{C}_{\mathrm{X}}$. The injected signal voltage is reduced by the capacitive divider, then multiplied by $A_{v}$. By comparing the output voltage vs. the injected signal, and knowing $A_{v}$ and the capacitance $C 2$, it is possible to calculate the remaining capacitance $\mathrm{C}_{\mathrm{X}}$. The capacitance measured this way was $22.6 \mathrm{pF}$. For the leakage test, the injection test point connected to $\mathrm{C} 2$ is grounded, so the total capacitance $\mathrm{C}_{\mathrm{T}}$ is the sum of $\mathrm{C} 2$ and $\mathrm{C}_{\mathrm{X}}$, or $\mathrm{C}_{\mathrm{T}}=23.6 \mathrm{pF}$.

The output voltage vs. time for the JFET is shown in Fig. 4. The output voltage varies by approximately $41 \mathrm{mV}$ over the 29 minute integration time. Using the calculated gain and capacitance with Eq. 1, the calculated leakage current is:

$$
I_{\text {leakage }}=0.59 \mathrm{fA}
$$




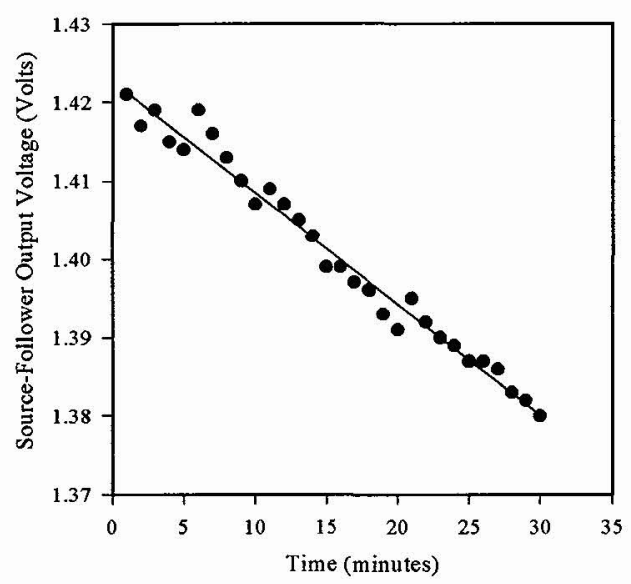

Fig. 4: The source-follower output voltage $V_{0}$ from the leakage current integrator shown in Fig. $2 b$, as a function of time for a rectangular JFET fabricated using the new process using a separate gate metalization and etch with an HF-based etchant. The total capacitance was measured as $23.6 \mathrm{pF}$.

\section{THE TRANSISTOR NOISE FOR THE OLD AND NEW PROCEDURES}

The input-referred voltage noise for a JFETs fabricated using the old process and a JFET fabricated using the new process are compared in Fig. 5. The old JFET was a ring structure $1250 \mu \mathrm{m}$ in diameter and $20 \mu \mathrm{m}$ long, with a capacitance of approximately $18 \mathrm{pF}$. The new JFETs is a rectangular structure $300 \mu \mathrm{m}$ wide and $100 \mu \mathrm{m}$ long with a capacitance of $21 \mathrm{pF}$. Both JFETs were biased at $1 \mu \mathrm{A}$ drain current; the drain voltage was $1.0 \mathrm{~V}$ for the old JFET and $0.6 \mathrm{~V}$ for the new JFET.

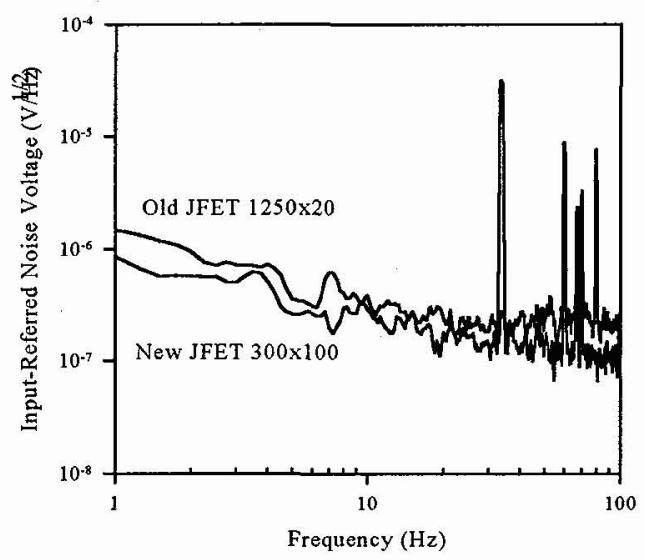

Fig. 5: The input-referred voltage noise for a ring JFET (1250 $\mu \mathrm{m}$ circumference by $20 \mu \mathrm{m}$ long) fabricated with the old, self-aligned process with an ammonium hydroxide-based etch, and the comparable noise for a rectangular JFET ( $300 \mu \mathrm{m}$ wide by $100 \mu \mathrm{m}$ long) fabricated with the new process using a separate gate etch and metalization with an HF-based etch. The noise spikes are $60-\mathrm{Hz}$ pickup and signals injected to calibrate the gain. 


\section{SUMMARY}

A new gate etch process has been developed that substantially improves the performance of JFETs intended for deep cryogenic operation. Where before the etch was done using an ammonium hydroxidebased etchant and using the gate metalization as a mask, the new procedure separates the photolithography for the gate etch and the gate metalization into two steps. In addition, a more isotropic HF-based etch is used. The new procedure reduced the gate leakage by many orders of magnitude, from leakage on the order of pA to less than one fA. The noise is also reduced somewhat.

The noise and leakage performance are closing in on those required for deep cryogenic space astronomy missions such as SIRTF. The fabrication of more JFETs using the new procedure, and further characterization of their gate leakage current and noise are underway.

\section{ACKNOWLEDGMENTS}

The measurements described in this paper were performed at the Jet Propulsion Laboratory, California Institute of Technology under a contract with the National Aeronautics and Space Administration. Reference herein to any specific commercial product, process, or service by trade name, trademark, manufacturer, or otherwise, does not constitute or imply endorsement by the United States Government or the Jet Propulsion Laboratory, California Institute of Technology.

\section{REFERENCES}

[1] Glidden R.M., Lizotte S.C., Cable J.S., Mason L.W., and Cao C., "Optimization of cryogenic CMOS processes for sub- $10^{\circ} \mathrm{K}$ applications," Conference on Infrared Readout Electronics, Orlando, Florida, 2121 April 1992, (Proc. of the SPIE/OA, 1992) pp. 2-39.

[2] R.K. Kirschman, S.V. Lemoff, and J.A. Lipa, "Evaluation of GaAs FETs for cryogenic readout," Conference on Infrared Readout Electronics, Orlando, Florida, 21-21 April 1992, (Proc. of the SPIE/OA, 1992) pp. 110-130.

[3] Goebel J.H., Weber T.T., Van Rheenen A.D., Jostad L.L., Kim J., and Gable B., "Cryogenic measurements of Aerojet GaAs n-JFETs," Conference on Infrared Readout Electronics, Orlando, Florida, 21-21 April 1992, (Proc. of the SPIE/OA, 1992) pp. 93-109.

[4] Balestra, F. "The Cryogenic Operation of Deep Submicron MOSFETs," Low Temperature Electronics and High Temperature Superconductivity, C. Claeys, et. al, Eds., Proc. Vol 95-9, The Electrochemical Society, Pennington, NJ, USA

[5] Camin, D.V., Fedyakin, N., Pessina, and G., Previtali, E., "Monolithic GaAs Preamplifiers for Cryogenic Particle Detectors," Low Temperature Electronics and High Temperature Superconductivity, C. Claeys, et. al, Eds., Proc. Vol 95-9, The Electrochemical Society, Pennington, NJ, USA

[6] Cunningham, T.J. and Fossum, E.R., "GaAs JFETs intended for deep cryogenic VLWIR readout electronics," Journal de Physique IV 4 C6, (1994) pp C6-147 to C6-152.

[7] Takebe, T., Tamamoto, T., Fujii, M., Kobayashi, K., "Fundamental Selective Etching Characteristics of $\mathrm{HF}+\mathrm{H}_{2} \mathrm{O}_{2}+\mathrm{H}_{2} \mathrm{O}$ Mixtures for GaAs," Journal of the Electrochemical Society, 140 (1993) pp 11691180 . 